\title{
Strengthening Mental Health Services by Implementing Telepsychiatric Treatments into Syrian Refugee Camps
}

\author{
Ahmad Hassan* \\ Yale University New Haven, USA \\ Submission: November 11 , 2018; Published: December 06, 2018 \\ *Corresponding author: Ahmad Hassan, Yale University New Haven, New Haven, Connecticut, USA
}

\begin{abstract}
The crisis in Syria has been ongoing for more than 7 years with no end in sight. A whole generation of Syrian children are growing up suffering from the severe mental health consequences of war, with many terming them the "lost generation". The mental health treatment options available to refugees living in camps is little to nonexistent. This systematic review analyzes the feasibility of utilizing telepsychiatry as a method of overcoming various obstacles, providing Syrian refugees with adequate mental health treatment until a larger plan may be put into action. The solution to the refugee crisis will likely take several decades, so it is imperative that an adequate option for mental health treatment be provided for refugees living in camps as soon as possible.
\end{abstract}

Keywords: PTSD; Depression; Syria; Refugees; Emotional disorders; Telepsychiatry

\section{Introduction}

Telemedicine is defined as a form of intervention via a telecommunication device between a medical practitioner and a patient that are separated by a distance APA [1]. It has been used to aid in diagnosis, monitoring patients, and intervening in medical treatment while providing the key advantage of offsetting the high costs associated with patients that are difficult to access [2]. Telemedicine can use a variety of different technologies, such as voice calling, video calling, video conferencing, and remote access technologies which allow physicians to gain information about the patient's health while being able to communicate with the patient and with other physicians.

Due to its flexible nature, telemedicine has wide-reaching potential, specifically in the field of mental health treatment. Telepsychiatry is the application of telemedicine to the field of psychiatry, and it involves delivering psychiatric assessment and care primarily through video conferencing. Currently, telepsychiatric services are most commonly at mental health facilities under the supervision of supervised staff, but an increasing number of at-home models are being accepted so long as they are in accordance with HIPAA standards. The two main barriers of access to psychiatric care are geographic location and cost, both of which are ever-present in Syrian refugee camps. This systematic review assesses the benefits and drawbacks of utilizing telepsychiatry as a possible treatment option to be implemented in refugee camps.
Patient-Provider Interaction: Psychiatry is a unique field in that it relies more heavily on the interactions between the patient and the provider. Not only is there a need for the psychiatrist to evaluate the patient's mental health through listening, speaking, and assessing nonverbal cues, but there is also the element of psychopharmacological treatment which requires constant monitoring by the provider in order to ensure no harmful side effects occur, and that the medication is not doing more harm than good. Due to the nature of the field, telepsychiatry relies mainly on video calling technologies rather than voice calling technologies, and a typical setup required to deliver telepsychiatric services includes a monitor, video camera, microphone, and speakers at both ends.

Cost of Telepsychiatric Services: It is unclear what effect telespsychiatry has on the cost of delivering psychiatric treatment. It appears that telepsychiatry, when applied to rural areas, results in the greatest financial benefit. This is supported by a study performed by Spaulding et al. which found that implementing telepsychiatric services in rural areas reduced costs by more than 70 percent [3]. Another study conducted by Rabinowitz et al. found that delivery of telepsychiatric services to nursing home residents in rural areas cut costs by about $\$ 30,000$ over the course of 278 telepsychiatric visits [4]. Other studies have found significantly less reduction in cost of telepsychiatry 


\section{Psychology and Behavioral Science International Journal}

versus traditional psychiatric treatment. However, another study conducted by Modai et al. [5] found that telepsychiatry costs more per year than traditional face-to-face services.

Access to Telepsychiatry: Telepsychiatry is promising in that it provides a substantial portion of the population with access to psychiatric services, overcoming barriers such as high costs, large distanced between patient and provider, and time limitations. A study conducted by Myers et al. [6] examined a telepsychiatry program which was implemented in the United States with the objective of reaching out to rural communities and concluded that was indeed effective at increasing rural communities' access to mental health services Meyers [7].

A separate study performed by Khasanshina et al. concluded that tele psychiatric services provided rural college students with adequate and effective mental health treatment while minimizing disruptions in daily activities Khasanshina [8]. Telepsychiatry has also been found to provide effective treatment in correctional facilities, where mental health illnesses are common but psychiatric services are lacking. Overall, it seems that telepsychiatry is effective at improving access of certain demographic communities to adequate mental health services.

Efficacy of Telepsychiatry: According to a recent study conducted by Maieritsch et al., telepsychiatry is equally as effective as face-to-face treatment in the case of treating patients with PTSD. The study involved veterans who were deployed in Iraq and Afghanistan and suffered from PTSD and analyzed the efficacy of cognitive processing therapy delivered through video-conferencing services [9]. A subsequent study undertaken by Hubley et al. [10]. conducted a systematic search of the literature available on telepsychiatry using the search terms, "telepsychiatry", "telemental health", "telecare", "telemedicine", "e-health", and "videoconferencing". It was found that overall, patients and providers are generally satisfied with telepsychiatric services, and it was concluded that a large evidence base supports telepsychiatric services as a delivery method for mental health services [11]. Given the apparent efficacy of telepsychiatry, along with the lack of adequate mental health treatment options available to Syrian refugees, it is necessary to determine whether those suffering from mental illness are willing to receive mental health treatment in the form of telepsychiatry.

Telepsychiatry as an Option for Syrian Refugees: Having been more than seven years since the advent of the Syrian conflict, the number of those displaced internally, along with refugees who are now located in neighboring countries, has reached staggering numbers. The UNHCR has currently identified approximately 13.5 million Syrians in need of humanitarian assistance, of which 5 million are refugees outside of the country and 6 million are internally displaced (ILO Employment Profile, 2014). Turkish government authorities estimate that more than half of Syrian refugees are in immediate need of mental health services yet remain untreated [12].

It is estimated that only five percent of the necessary mental health services is provided for refugees in Syria, Lebanon, and
Turkey [1]. One of the greatest obstacles preventing Syrian refugees from receiving mental health treatment is the presence of a language barrier, as most Syrian refugees only speak Arabic, and there is a severe lack of Arabic-speaking mental health professionals in the region due to the small number of certification-granting programs in the region. Additional obstacles include access to refugees and high costs of hiring mental health professionals to stay in the area and follow up with patients [2]. The sheer number of Syrian refugees entering neighboring countries puts pressure on the health-care system and economy of countries already suffering from weak services and infrastructure [13].

Administering tele psychiatric services in Syrian refugee camps would almost certainly provide Arabic-speaking refugees access to Arabic-speaking mental health professionals who would otherwise not be available. Additionally, this would ease some financial strain placed on neighboring countries; economies due to the amount of resources which must be allocated towards refugees by alleviating a portion of the cost to deliver mental health treatment to refugees living in camps. Any geographical and regional constraints related to distance and danger would be overcome, providing refugees-especially children- with adequate mental health treatment.

\section{Conclusion}

Several factors contribute to the lack of mental health treatment available in refugee camps. These include: limited funding by the government; geographical constraints; regional violence; and access to Arabic-speaking mental health professionals. Telepsychiatry significantly reduces costs in delivering mental health services, especially in rural areas. It overcomes all geographical and regional constraints and provides refugees with access to Arabic-speaking therapists that would otherwise not be available. With some studies suggesting that as little as 5 percent of refugees are receiving proper mental health services, telepsychiatry is a critical step in moving forward with the refugee crisis, allowing for the feasible and rapid implementation of adequate mental health services to Syrian refugees [13-15].

\section{References}

1. American Psychiatric Association (1994) Diagnostic and Statistical Manual of Mental Disorders (4 ${ }^{\text {th }}$ edn.), Washington, DC American Psychiatric Association, USA.

2. Kuo G M, Ma JD, Lee KC, Bourne PE (2011) Telemedicine, Genomics and Personalized Medicine: Synergies and Challenges. Current Pharmacogenomics and Personalized Medicine 9(1): 6-13.

3. Spaulding R, Belz N, DeLurgio S (2010) Williams A. R. Cost Savings of Telemedicine Utilization for Child Psychiatry in a Rural Kansas Community. Telemed J E Health 16(8): 867-871.

4. Rabinowitz T, Murphy KM, Amour JL, Ricci MA, Caputo MP (2010) Newhouse P. A. Benefits of a Telepsychiatry Consultation Service for Rural Nursing Home Residents. Telemed J E Health 16(1): 34-40.

5. Modai IM, Jabarin R, Kurs P, Barak I, Hanan L Kitain (2006) Cost Effectiveness, Safety, and Satisfaction with Video Telepsychiatry versus Face-to-Face Care in Ambulatory Settings. Telemedicine and e-Health 12(5): 515-520. 


\section{Psychology and Behavioral Science International Journal}

6. Myers K, Cain S (2008) Practice Parameter for Telepsychiatry with Children and Adolescents. Journal of the American Academy of Child and Adolescent Psychiatry 47(12): 1468-1483.

7. Myers K, Valentine J, Morganthaler R, Melzer S (2006) Telepsychiatry with Incarcerated Youth. J Adolesc Health 38(6): 643-648.

8. Khasanshina E V, Wolfe WL, Emerson EN, Stachura ME (2008) Counseling Center-based Telemental Health for Students at a Rural University. Telemedicine and e-Health 14(1): 35-41.

9. Maieritsch KP, Smith TL, Hessinger JD, Ahearn EP, Eickhoff JC (2016) Randomized controlled equivalence trial comparing videoconference and in person delivery of cognitive processing therapy for PTSD Journal of Telemedicine and Telecare, 22(4), 238-243.

10. Hubley S, Lynch SB, Schneck C, Thomas M, Shore J (2016) Review of key telepsychiatry outcomes. World journal of psychiatry, 6(2): 269282

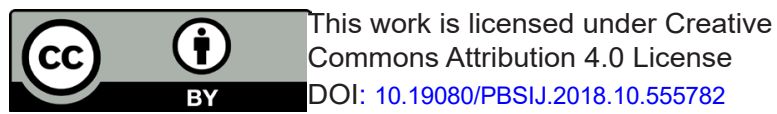

11. Icduygu, Ahmet (2015) Syrian Refugees in Turkey: The Long Road Ahead. Migration Policy Institute.

12. Vliet, Sam van, Guita Hourani (2014) Regional Differences in the Conditions of Syrian Refugees in Lebanon. Civil Society Review.

13. Almoshmosh N (2015). Highlighting the mental health needs of Syrian refugees. Intervention 13(2): 178-181.

14. Alpak, Gokay, Bulbul F, Sagaltici E, Bez Y, et al. (2014) Post-Traumatic Stress Disorder among Syrian Refugees in Turkey: A Cross-Sectional Study. International Journal of Psychiatry in Clinical Practice 19(1): 45-50.

15. (2014) Assessment of the Impact of Syrian Refugees in Lebanon and Their Employment Profile. International Labour Organization Regional Office for the Arab States. pp.48.

\section{Your next submission with Juniper Publishers} will reach you the below assets

- Quality Editorial service

- Swift Peer Review

- Reprints availability

- E-prints Service

- Manuscript Podcast for convenient understanding

- Global attainment for your research

- Manuscript accessibility in different formats

( Pdf, E-pub, Full Text, Audio)

- Unceasing customer service

Track the below URL for one-step submission

https://juniperpublishers.com/online-submission.php 